\title{
LA TERMINOLOGÍA EN LAS INSTITUCIONES DE LA UE: DE LA FRAGMENTACIÓN A LA CONVERGENCIA ${ }^{1}$ Javier Muñoz Martin María Valdivieso Blanco \\ Consejo de la Unión Europea, Bruselas, Bélgica
}

\begin{abstract}
In a period of terminological convergence in the EU, this article is meant to provide a brief overall assessment of EU terminology. For that purpose, firstly, it describes from a general perspective the operation and structure of the Translation Unit of the EU Council, gives some specific significant aspects in EU institutions and, lastly, shows the principle materialisation of this terminological research in the EU: the terminology database IATE.
\end{abstract}

KEYWORDS: terminology, EU Council, EU, database.

\section{RESUMEN}

En una época de convergencia terminológica en la UE, este artículo pretende ofrecer un panorama de conjunto de la terminología en la UE. Para ello, en primer lugar se describe desde una perspectiva general el funcionamiento y estructura de la unidad de traducción del Consejo de la UE, a continuación se ofrecen algunos aspectos significativos en las instituciones de la UE y por último, se presenta la principal materialización de esta investigación terminológica en la UE: la base de datos terminológica IATE.

PALABRAS CLAVE: terminología, Consejo de la UE, UE, base de datos.

\section{OBSERVACIÓN PRELIMINAR}

El panorama que aquí vamos a exponer procede de nuestra visión de las cosas como profesionales de la traducción sobre el terreno. En nuestra

\footnotetext{
1 La exposición de hechos y opiniones que hacen los autores en la presente conferencia es a título personal y no representa la posición oficial de las instituciones de la UE ni coincide necesariamente con ella.
} 
institución, el Consejo de la UE, somos traductores que realizan actividades terminológicas. No somos, por tanto, teóricos ni especialistas en terminología.

Por otra parte, es un panorama percibido desde la óptica del Consejo. Lo que ocurre es que, debido a la convergencia que se está produciendo en estos momentos en la terminología de las distintas instituciones, creemos que esta visión de partida es un medio válido para ofrecer un panorama de conjunto de la terminología en la UE.

\section{PRESENTACIÓN DEL ESQUEMA}

Vamos a partir del marco general que determina nuestro trabajo, expondremos después una serie de rasgos característicos, aunque no privativos, de nuestro campo de actividad y les presentaremos, por último, la principal materialización de esa actividad en una base de datos terminológica.

\section{MARCO GENERAL}

\subsection{RAZÓN DE SER DE LA TERMINOLOGÍA: EL MULTILINGÜISMO}

Hasta hace pocos años, la Unión Europea contaba con veintiuna lenguas oficiales y de trabajo (ES, CS, DA, DE, EE, EL, EN, GA, FR, IT, LV, LT, HU, MT, NL, PL, PT, SK, SL, FI, SV), con cuatro más en perspectiva (BG, RO, TR, CR) de los países que eran candidatos llegan a entrar. Ello supone actualmente un total de veinticinco lenguas con tres alfabetos (latino, griego y cirílico). La ONU, con 191 países miembros, tiene "sólo" seis lenguas oficiales (EN, FR, ES, RS, AR y CH).

En la Unión Europea, además, se da la paridad absoluta de las lenguas, es decir, que todas tienen el mismo valor jurídico. Formalmente, no hay un texto original y unos textos traducidos.

Siendo tan numerosas las lenguas de la Unión Europea, es evidente el riesgo de que la comunicación con el ciudadano se tiña de confusión, cosa que no siempre consigue evitarse. Esto se debe a las interferencias derivadas de los numerosos cruces de lenguas, unidas a la opacidad inherente al lenguaje administrativo y técnico. Por ello, la Unión ha iniciado desde hace tiempo una reflexión sobre la calidad de la redacción y se ha dotado de normas y de códigos con los que se intenta que la claridad y la precisión de la comunicación con el ciudadano garanticen la transparencia que requiere todo sistema democrático. 


\subsection{LA ESTRUCTURA ORGÁNICO-ADMINISTRATIVA}

El Consejo dispone de una unidad de traducción por lengua, cada una con un equipo de terminología. Los distintos equipos están coordinados por una unidad de terminología central, que impulsa y orienta el trabajo.

\subsubsection{Traducción e interpretación}

Aquí hay que hacer una puntualización. Hasta ahora en el Consejo, como en las demás instituciones, traducción e interpretación han venido siendo dos actividades realizadas por equipos distintos, con una organización administrativa diferente. La colaboración entre estos dos colectivos es hoy por hoy limitada, pero es de esperar que se potencie, por ejemplo, en relación con la base terminológica interinstitucional de la que hablaremos luego. Pero aquí sólo nos referimos a la traducción.

1.3. Naturaleza de la terminología en el Consejo. Principales FUNCIONES

\subsubsection{Ayuda directa a la traducción}

La terminología se concibe como instrumento de la traducción. El equipo de terminología debe atender las consultas de los traductores y ayudarles a encontrar soluciones a los problemas de traducción. Podríamos decir que ésta es su principal función.

\subsubsection{Gestión de una base de datos terminológica}

El aprovechamiento, la organización y sistematización deseables de ese caudal puesto al servicio del traductor desemboca de forma natural en un banco de datos de la institución. Así pues, si bien la gran tarea de los equipos de terminología del Consejo es la gestión de una base terminológica, esta labor no es, en realidad, más que una extensión, por así decirlo, de la función primordial de ayuda a la traducción. Este papel instrumental, esta fuerte vinculación determinan, según veremos luego, cómo se enfoca la alimentación de la base terminológica. 


\subsubsection{Otras tareas}

Además de las dos funciones principales que acabamos de ver, la ayuda a la traducción y la gestión de la base terminológica, los terminólogos de la unidad desempeñan diversas tareas como las relacionadas con la fijación de fórmulas establecidas en el Consejo, la traducción de los cargos gubernamentales de los Estados miembros y la búsqueda de documentación.

\section{ALGUNOS ASPECTOS SIGNIFICATIVOS DE LA TERMINOLOGÍA EN LAS INSTITUCIONES EUROPEAS}

A continuación vamos a exponer, a título de ejemplo, una serie de rasgos que, si bien son característicos de nuestra terminología, ofrecen perfiles que pueden ser de interés para los profesionales de la traducción en general.

\subsection{LA TRADUCCIÓN, ALFA Y OMEGA DE LA TERMINOLOGÍA}

Una primera característica distintiva de nuestra terminología es que no es autónoma; la terminología institucional no es un fin en sí misma, sino un medio para encontrar soluciones a problemas de traducción. Esto se refleja en dos aspectos:

* Los terminólogos: son o han sido traductores de la casa, no son necesariamente especialistas en terminología;

* Contenido: la terminología toma como fuente muy frecuente la traducción, por ejemplo, los textos legislativos traducidos de la UE. Esto es problemático, ya que puede haber la tentación de dar por bueno un término que aparece en un texto traducido sin contrastarlo ni someterlo a la validación terminológica necesaria.

\subsection{LA VARIEDAD DE REGISTROS Y TEMAS}

El registro que impera en nuestra traducción es el formal, pero con una gran variedad de estilos, desde la declaración política hasta la decisión administrativa o el acto puramente jurídico. No en muchas organizaciones tiene uno ocasión de traducir desde un reglamento sobre derechos antidumping para las importaciones de ácido tricloroisocianúrico procedentes de China, hasta una cita de Tucídides en griego clásico recogiendo un discurso de Pericles (la que encabezaba el proyecto inicial de Constitución Europea), o decidir si lo que compuso Beethoven se llama "Oda" o "Himno a la Alegría" (versión que aparece en el Tratado Constitucional). 
Pero si por algo se distingue nuestra traducción, y por tanto nuestra terminología, es por la extraordinaria variedad de temas: agricultura, fiscalidad, política exterior, telecomunicaciones, derecho internacional, cooperación judicial, etc., etc. Por tanto, una de las cualidades indispensables de nuestros terminológos ha de ser la capacidad para documentarse sobre prácticamente cualquier tema.

Esta diversidad temática se orienta en dos vertientes con necesidades contradictorias:

- La temática técnico-jurídica requiere gran precisión terminológica, uniformidad de los términos empleados y uso de definiciones rigurosas.

- La temática política, por el contrario, suele estar impregnada de vaguedad. En este terreno, un exceso de precisión puede, por ejemplo, dificultar el acuerdo político sobre un tema conflictivo.

\subsection{EL PROBLEMA DE LA AUTORIDAD. ¿QUIÉN MANDA EN LAS PALABRAS?}

Se plantean aquí dos cuestiones que se solapan: la de la autoridad lingüística per se (quién decide qué palabra hay que utilizar para denominar un concepto determinado) y la de la propiedad del texto (hasta qué punto el redactor del texto original o la propia institución pueden decidir, con criterios políticos u otros, sobre cuestiones técnicas de traducción). Y es que la terminología institucional está condicionada por una serie de factores y de fuentes de autoridad particulares con los que hay que contar indefectiblemente. El terminólogo ha de evaluar en cada caso la importancia relativa de factores en conflicto y establecer una jerarquía de autoridad que lo guíe en su decisión.

\subsection{LA INSTITUCIÓN. AUTORIDAD LINGÜÍSTICA Y AUTORIDAD ADMINISTRATIVA.}

En algunos casos pueden acuñarse términos de forma oficial. Tenemos, por ejemplo, las etiquetas supralingüísticas o multilingües, que se fijan de antemano para todas las lenguas y le vienen así impuestas al traductor. Ejs.: EuropeAid, Erasmus, e-Europe, Phare, Regio (a menudo, nombres de programas o proyectos comunitarios), euro, cent. Lo que se intenta con ellas es tener una denominación, si no única, tan similar en todas las lenguas que equivalga a hacer abstracción del a veces molesto multilingüismo. El resultado puede en ocasiones violentar la lengua final y poner al traductor en situaciones incómodas. 
Cuando un término figura ya en la legislación comunitaria vigente, tenemos que plantearnos hasta qué punto nos condiciona para establecer una equivalencia terminológica. Cuando el término se acuña en un acto legislativo con una definición (esto suele ocurrir, por ejemplo, en los primeros artículos de reglamentos, directivas y convenios), es preceptivo utilizar ese mismo término después, en las referencias a dicho acto.

\subsection{EL ESPECIALISTA}

La naturaleza técnica de muchos de nuestros textos confiere una clara autoridad a los especialistas, técnicos y estudiosos. En nuestra terminología es, pues, fundamental mantener buenos y numerosos contactos con profesionales de distintos campos, profesores universitarios, funcionarios de ministerios, etc. Esta relación, que puede resultar muy fructífera, conlleva también un problema: el especialista tiene una clara competencia técnica, pero no necesariamente lingüística. Ello da lugar a la plétora de calcos y préstamos que se encuentran en el lenguaje científico y técnico actual. El terminólogo ha de llegar a un difícil equilibrio en este sentido, aportando su propia competencia lingüística, e intentar acordar con el especialista soluciones que, siendo técnicamente correctas, lo sean también lingüísticamente.

\subsection{LOS REPRESENTANTES DE LOS GOBIERNOS}

El Consejo es una institución en la que participan los representantes de los gobiernos de la UE. Éstos desean a veces sugerir modificaciones en la terminología utilizada por la institución, para lo cual transmiten, a través de diplomáticos o técnicos de los ministerios, "observaciones" sobre un texto traducido. Ahora bien, un traductor de la UE se debe estatutariamente a su institución. Es más, tiene la obligación de no pedir ni aceptar directamente instrucciones de un gobierno nacional. Esto significa que las observaciones de los gobiernos sólo adquieren carácter obligatorio cuando las hacen suyas las estructuras administrativas de la institución. En la práctica, suele tratarse de observaciones técnicas que se incorporan sin problemas. 


\subsection{EL PROCESO LEGISLATIVO}

La propia naturaleza del proceso legislativo de la UE puede plantear también dilemas o conflictos. Una ley comunitaria (directiva, reglamento, etc.) suele nacer como propuesta de la Comisión, quien, en su función de iniciativa legislativa, la transmite al Consejo y al Parlamento Europeo para que la debatan. Para lo que importa a la traducción, este procedimiento supone que el texto español, por ejemplo, va pasando de una institución a otra, cada una de las cuales trabaja sobre él modificándolo de distintas maneras. En teoría, cada institución es dueña de su traducción, si bien la lógica aconseja aprovechar al máximo el trabajo ya hecho y mantener lo más posible el texto recibido de la institución anterior. Pero ¿qué ocurre en caso de discrepancia? ¿Qué hacemos si la propuesta de la Comisión contiene un término con el que el Parlamento no está de acuerdo pero que el Consejo sí acepta? En la práctica, esta situación se salva mediante el diálogo interinstitucional y el respeto del trabajo anterior, pero lo cierto es que este dilema no tiene hoy por hoy una solución formal clara.

\subsection{DILEMAS DE LA TRADUCCIÓN INSTITUCIONAL}

\subsection{1. "Principios de terminología" frente a "necesidades prácticas"}

El hecho de que, como hemos visto, nuestra labor terminológica sea instrumental y no un fin en sí misma significa que los criterios de utilidad práctica priman frente a los principios teóricos. Estos principios siguen siendo un ideal de referencia, y de hecho es notable la evolución en este sentido de unos años acá. Se ha pasado de hacer una terminología esencialmente práctica e intuitiva a una terminología igualmente práctica pero más rigurosa, con normas y objetivos prefijados y con una mayor adhesión al marco teórico de la ciencia terminológica. Pero la jerarquía de necesidades y valores sigue siendo la misma.

\subsubsection{La dificultad de tratar conjuntos temáticos coherentes}

Nuestro trabajo terminológico no suele ser anticipatorio. Si no hay una necesidad de traducción concreta, no se hace la investigación ni la ficha terminológica. Esto significa que nunca aspiramos a la coherencia exhaustiva de los temas cubiertos. Por ejemplo, si en una declaración política del Consejo figura el término inglés Daghestani, o Shia, o Roma, entonces nos plantearemos la equivalencia española y completaremos la ficha correspondiente. Pero esto nunca nos llevará a cubrir todo el campo semántico de los gentilicios, los 
grupos religiosos o los grupos étnicos. Nuestra base de datos, pues, cubre la realidad de manera sólo parcial e incompleta, sin más coherencia en este sentido que la utilidad práctica de su contenido para la actividad de la UE.

\subsubsection{Términos, palabras, fórmulas}

El trabajo de las terminologías institucionales no se limita, como el de la terminología formal, a las unidades de los lenguajes especializados, los términos propiamente dichos. Numerosas entradas de la base terminológica son vocablos del lenguaje general, expresiones o fórmulas relativamente largas que es necesario unificar y fijar en aras de la coherencia legislativa. Esta es una manifestación más del lado documental de nuestra terminología. Dos ejemplos de esto pueden ser una fórmula como "Sin perjuicio de lo dispuesto en el artículo 8, la Comisión adoptará las medidas previstas siempre que sean conformes al dictamen del Comité", y términos del eurolecto como "conclusiones" y "acción común".

\subsection{4. ¿EFichas monoconceptuales ofichas multilingües?}

Teóricamente, una ficha terminológica debería albergar un único concepto. Ahora bien, el principio del multilingüismo de la UE aconseja que toda ficha tenga el mayor número posible de lenguas oficiales. Dado que casi nunca se da la correspondencia exacta entre dos términos de dos lenguas distintas, la idea de hacer una ficha multilingüe que contenga un solo concepto raya en la utopía.

\subsubsection{El terminólogo, ¿notario o creador?}

La terminología institucional se ve obligada a menudo a participar en la creación neológica. Esto es así, por un lado, porque la actividad de la UE requiere denominaciones propias para realidades propias: entes administrativos o políticos (Tribunal General), figuras jurídicas (orden de detención europea), programas y proyectos (Erasmus, Media, eLearning, etc.), conceptos políticos (comitología, subsidiariedad), etc. Es la jerga comunitaria o eurolecto. Por otro lado, porque la UE aborda temas de actualidad y campos científicos y técnicos con conceptos nuevos aún no fijados de forma léxica. En todos estos casos, el terminólogo ha de optar por asumir una función, bien "notarial", bien de creación. En el primer caso, se limita a tomar nota de términos que otros han creado, ya sean especialistas o hablantes en general, y a validarlos y difundirlos. 
En el segundo caso, osará concebir un término ex novo para denominar la nueva realidad. Ésta es una de las funciones más trascendentales de su actividad, ya que el terminólogo ocupa un lugar en la elaboración legislativa que le confiere cierta autoridad lingüística (no hay que olvidar que un 70\% de la legislación nacional deriva, directa o indirectamente, de la comunitaria). También ha de intervenir el terminólogo para facilitar o encauzar la convergencia cuando se produce una proliferación de soluciones para un mismo problema de traducción (ej.: bullying: matonismo, tiranización, acoso, hostigamiento, intimidación, etc.; ocurre lo mismo con rogue state). Cuando esto ocurre, de una variedad de soluciones que son igualmente válidas conviene optar por una para que la expresión del concepto no se disperse excesivamente.

\section{LA BASE DE DATOS TERMINOLÓGICA: IATE}

\subsection{LOS ANTECEDENTES DE IATE EN EL CONSEJO: TIS}

Vamos a ver ahora cómo se materializa todo esto en el instrumento fundamental de la terminología de la Unión Europea: su base de datos.

El antepasado en el Consejo de la actual base de datos, IATE, es TIS, una base interactiva anterior a la aparición de internet. Si bien se concibió como base de datos terminológica (Terminological Information System), cumplía, al mismo tiempo, una importante función de documentación. Allí se almacenaban frases enteras o títulos de reglamentos, aunque ello tuviera poco que ver con la terminología, porque era útil y necesario. TIS plasmaba fielmente el principio de una base alimentada a partir de los problemas concretos de traducción que surgían en unas circunstancias en las que primaba el dar con una solución a un problema traductológico concreto, sin preocuparse excesivamente de la coherencia de la base en conjunto. Como veremos, algo de este principio pervive hoy día, aunque es cierto que ha habido una gran evolución.

Hacia finales de los años 90, ya se disponía con facilidad de cuatro instrumentos de consulta fundamentales que ofrecían documentación:

1. CELEX (posteriormente integrado en EURLEX), la base que contiene la legislación comunitaria.

2. AIS, un archivo multilingüe de uso interno que contiene los documentos no confidenciales del Consejo.

3. Servidores institucionales internos, con otro tipo de documentación.

\section{Internet.}

A principios de los años 2000, se introdujeron, además, las primeras memorias de traducción con el sistema TRADOS. 
Con estos nuevos instrumentos a disposición de los traductores, la base terminológica podía dejar de ser almacén documental y centrarse más en el contenido puramente terminológico. Era el momento de acometer la obra de limpieza y reorganización que el paso de los años había hecho necesaria. Por eso, en la última etapa de TIS, los trabajos de racionalización de conjuntos o familias de fichas y la eliminación de fichas ya inútiles o duplicadas ocuparon un lugar primordial en la actividad terminológica del Consejo. Pero ya había llegado para TIS la hora del relevo. TIS era entonces una base con 200.000 entradas conceptuales y con un $45 \%$ de fichas en 3 o más lenguas, cuyas soluciones no pretendían tener aplicación universal sino responder a las necesidades que planteaban los documentos del Consejo.

\subsection{IATE}

\subsubsection{Punto de partida}

Cuando se crea IATE (Inter-Agency Terminology Exchange y posteriormente InterActive Terminology for Europe), la situación puede resumirse así:

3.2.1.1. Diversidad de bases terminológicas institucionales

- Comisión: Eurodicautom

- Consejo: TIS

- Parlamento Europeo: EUTERPE

- Centro de Traducción: EUROTERMS

- Tribunal de Justicia: CDTERM

- Comité Económico y Social/Comité de las Regiones

- BEI

3.2.1.2. Disparidad de dimensiones de las bases existentes

Veamos algunos ejemplos:

Eurodicautom: $\quad 1.200 .000$ conceptos multilingües

EUTERPE: 260.000

TIS: $\quad 200.000$

3.2.1.3. Disparidad de filosofías subyacentes, de prácticas, de necesidades, de medios 
Cada institución había desarrollado unos usos, a partir de unos planteamientos que respondían a sus necesidades, a sus condiciones, a sus circunstancias, etc. Por ejemplo, Eurodicautom tendía a ofrecer una gran cantidad de fichas, aunque la información no fuera exhaustiva, y la definición de un concepto era dependiente de la lengua en la que se expresaba. Tenía además un contenido más bien técnico-científico. En el otro extremo, TIS creaba un número de fichas mucho menor, pero con una tendencia, en su última etapa, ya reseñada, a introducir mucha más información en ellas. Su contenido tenía un carácter más jurídico e institucional.

\subsubsection{Convergencia}

Con estas disparidades enfrente, la decisión tomada a finales de los años 90 de ir a una convergencia de la actividad terminológica en las instituciones era problemática. En principio, se presentaban dos posibilidades principales:

1. Mantener las bases existentes y crear un portal de acceso.

2. Fundir en una sola todas las bases existentes. Esta fue la opción elegida.

IATE debía ser la única base de datos terminológica para:

- una mayor facilidad de consulta del acervo terminológico común

- una mayor calidad

- una menor duplicación de esfuerzos.

Los usuarios previstos eran:

- $\quad$ el personal de las instituciones

- usuarios externos: traductores, ministerios, especialistas, etc.

Sobre todo, IATE debía ser un instrumento fundamental de la armonización terminológica en las instituciones europeas.

\subsection{3. ¿Qué es LATE?}

1. IATE es una base terminológica común e interactiva de las instituciones y otros entes de la UE, concebida como el principal instrumento para la elaboración multilingüe de textos comunitarios, especialmente los legislativos.

2. Su función concreta es ofrecer información terminológica pertinente, fiable, comprobada y de fácil consulta.

3. Es un producto elaborado por una empresa privada, en consulta y colaboración con especialistas de las instituciones. 
4. Está inicialmente constituida por yuxtaposición de los fondos de las bases heredadas.

5. Es directamente modificable. Su programa y contenido están en un servidor al que se accede desde las instituciones.

6. Tiene un procedimiento propio de validación y comunicación que debe garantizar su calidad.

\subsubsection{Algunas cifras de LATE}

\begin{tabular}{|l|l|l|l|}
\hline Conceptos (fichas): & 1.500 .000 & & \\
\hline & & términos: & 7.000 .000 \\
\hline Entradas: & $8.000 .000:$ & abreviaturas: & 500.000 \\
\hline & & frases: & 200.000 \\
\hline Definiciones: & 800.000 & & \\
\hline
\end{tabular}

\subsubsection{Estructura de una pantalla de búsqueda}

Actualmente, el uso de IATE está limitado a las instituciones. El idioma de comunicación es exclusivamente inglés. Al entrar en la base, al usuario se le ofrece una pantalla de búsqueda con una serie de ventanas. Los elementos más destacables de una pantalla de búsqueda son los siguientes:

- Selección del idioma fuente.

- Selección del idioma meta.

- Selección de la institución en cuyas fichas se va a realizar la búsqueda. Puesto que la base está alimentada por distintas instituciones, podemos filtrar la que nos interesa o buscar el término en las fichas de todas ellas.

- Tipo de término buscado: palabra, abreviatura, frase, etc.

- Término buscado.

- Grado de fiabilidad exigido para el resultado. También aquí podemos querer ver todos los resultados o sólo aquéllos con una etiqueta de mayor fiabilidad.

- Materia en la que se desea hacer la búsqueda. Una vez más, podemos introducir un factor de filtrado o hacer una búsqueda general.

Si la búsqueda efectuada obtiene resultados positivos, IATE nos ofrece una lista de lo encontrado. 


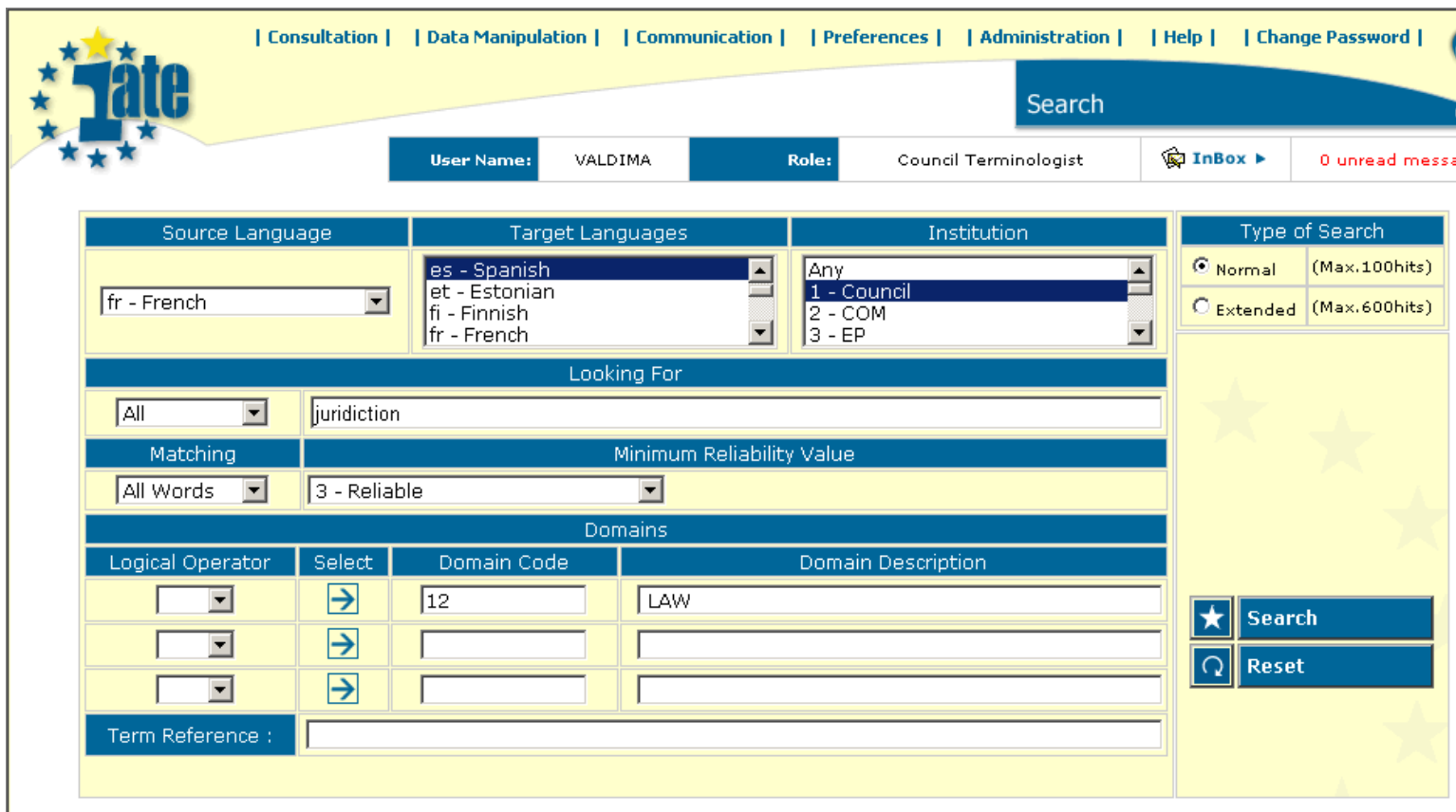

Fig. 1: LATE-Pantalla de búsqueda

\subsubsection{Estructura de una pantalla de resultados}

Es una pantalla que presenta una visión simplificada de las fichas encontradas por IATE con los criterios de búsqueda que hemos seleccionado. Por cada ficha nos ofrece:

1. El número de ficha. Permite entrar en la ficha en un formato de impresión.

2. Las materias a las que pertenece el término buscado. Naturalmente, un mismo término puede corresponder a materias distintas, lo que en IATE significa encontrarlo en fichas también distintas.

3. Las lenguas en las que aparece el término. La ficha ideal, completa, ofrecería las 21 lenguas oficiales de la UE, pero en muchos casos nos bastarán los resultados de la correspondencia lengua $O R \rightarrow E S$, por lo que habremos filtrado convenientemente.

4. El término en las distintas lenguas. Los sinónimos se tratan como términos distintos para un mismo concepto y se ofrecen cada uno con un código de fiabilidad.

5. Código de fiabilidad. IATE dispone de cinco niveles de fiabilidad para un término en cada idioma (de 0 a 4 ). 
ENTREC ULTURAS Número 1. ISSN: 1989-5097. Fecha de public ación: 27-03-2009

6. La institución que ha introducido cada versión lingüística.

Esta lista de resultados es, pues, sólo un "escaparate" de la ficha, con la información mínima. Para recabar la información completa, debemos entrar en la ficha propiamente dicha.

| Consultation | | Data Manipulation | | Communication | | Administration | | Help | | Change Password |

Your search returned $\bullet 1$ Hit.

es - Spanish

cs - Czech

da - Danish

de - German

el - Greek

en - English

et - Estonian

fi - Finnish

fr - French

hu - Hungarian

it - Italian

It - Lithuanian

Iv - Latvian

mt - Maltese

$\mathrm{nl}$ - Dutch

pl - Polish

pt - Portuguese

sk - Slovak

sl - Slovenian

sv - Swedish

ga - Irish
Defensor del Pueblo europeo

veřejný ochránce práv

ombudsmand

Ombudsmanden

ombudsmandsinstitution

Den Europæiske Ombudsmand

Bürgerbeauftragter

Europäischer Bürgerbeauftragter

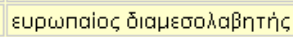

Ombudsman

European Ombudsman

ombudsman

Euroopa ombudsman

oikeusasiamies

Euroopan oikeusasiamies

Euroopan unionin oikeusasiamies

médiateur

médiateur européen

európai ombudsman

mediatore

mediatore europeo

Europos ombudsmenas

Eiropas ombuds

Ombudsman Ewropew

ombudsman

Europese ombudsman

Europejski Rzecznik Praw Obywatelskich

Provedor de Justiça Europeu

Európsky ombudsman

Evropski varuh človekovih pravic

ombudsmannen

EU-ombudsmannen

Europeiska ombudsmannen

Ombudsman Eorpac 


\subsubsection{Estructura de una ficha}

Una ficha abierta puede ofrecer simultáneamente dos lenguas en pantalla. Destacaremos en ella los siguientes elementos:

1. Nivel de entrada (común a todas las lenguas). Contiene las materias, información administrativa y posibles remisiones a fichas relacionadas.

2. Nivel de lengua. La información fundamental es la definición y su fuente.

3. Nivel del término. Fundamentalmente contiene:

El término o términos, si la ficha ofrece sinónimos en una lengua, con su fuente.

Citas.

Comentarios.

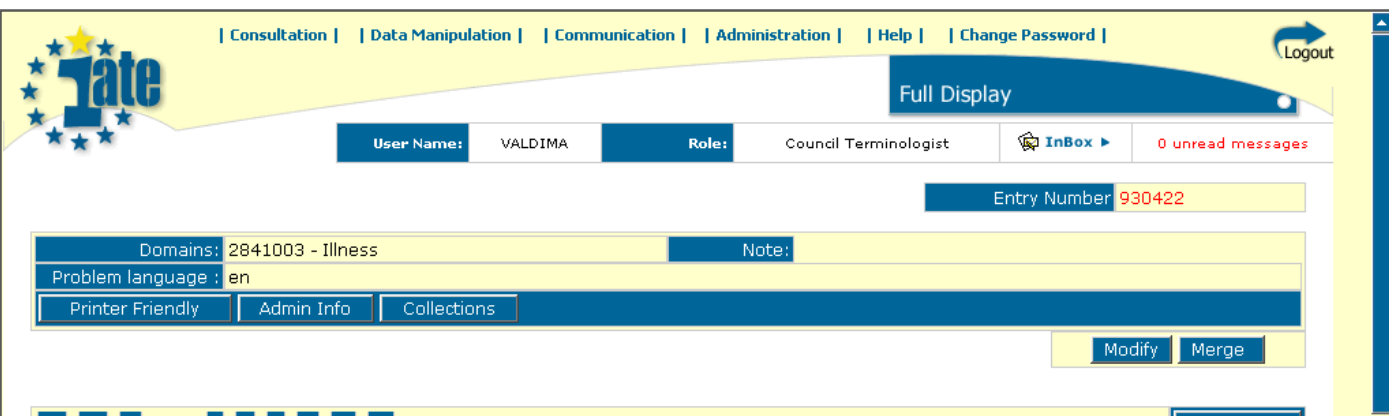

da de el en es fil frr it nl pt $\mathbf{5 V}$

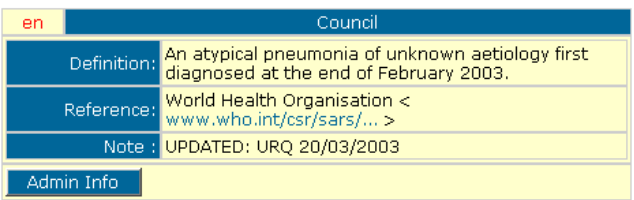

New Term 


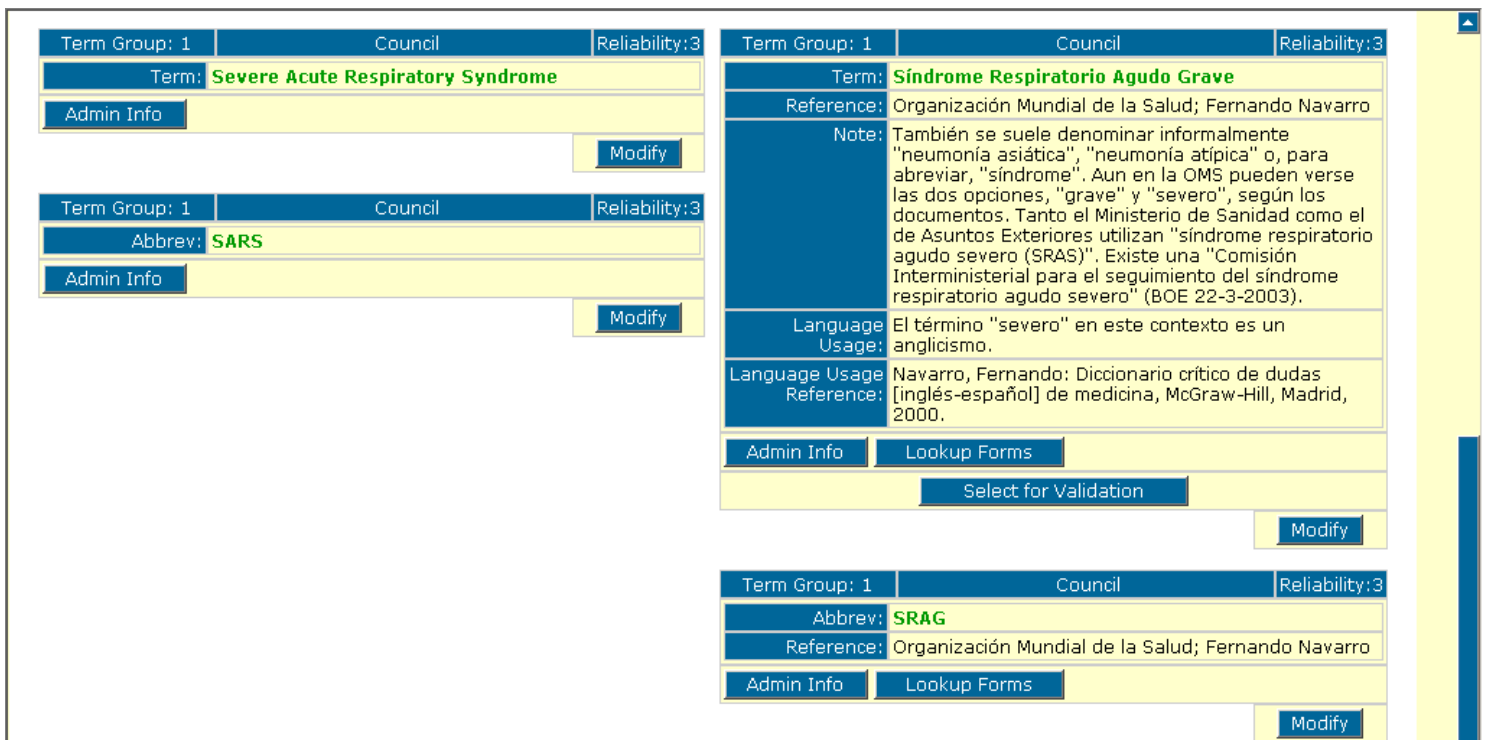

Fig. 3: LATE-Ficha abierta

\subsubsection{Avisos}

En la ficha, los terminólogos pueden colgar avisos (marks en inglés) destinados a otros terminólogos sobre cuestiones concretas de la ficha, p. ej., propuestas, suministro de información, breves comentarios, etc. Esta función de comunicación es un instrumento fluido y muy eficaz para el trabajo en equipo. 


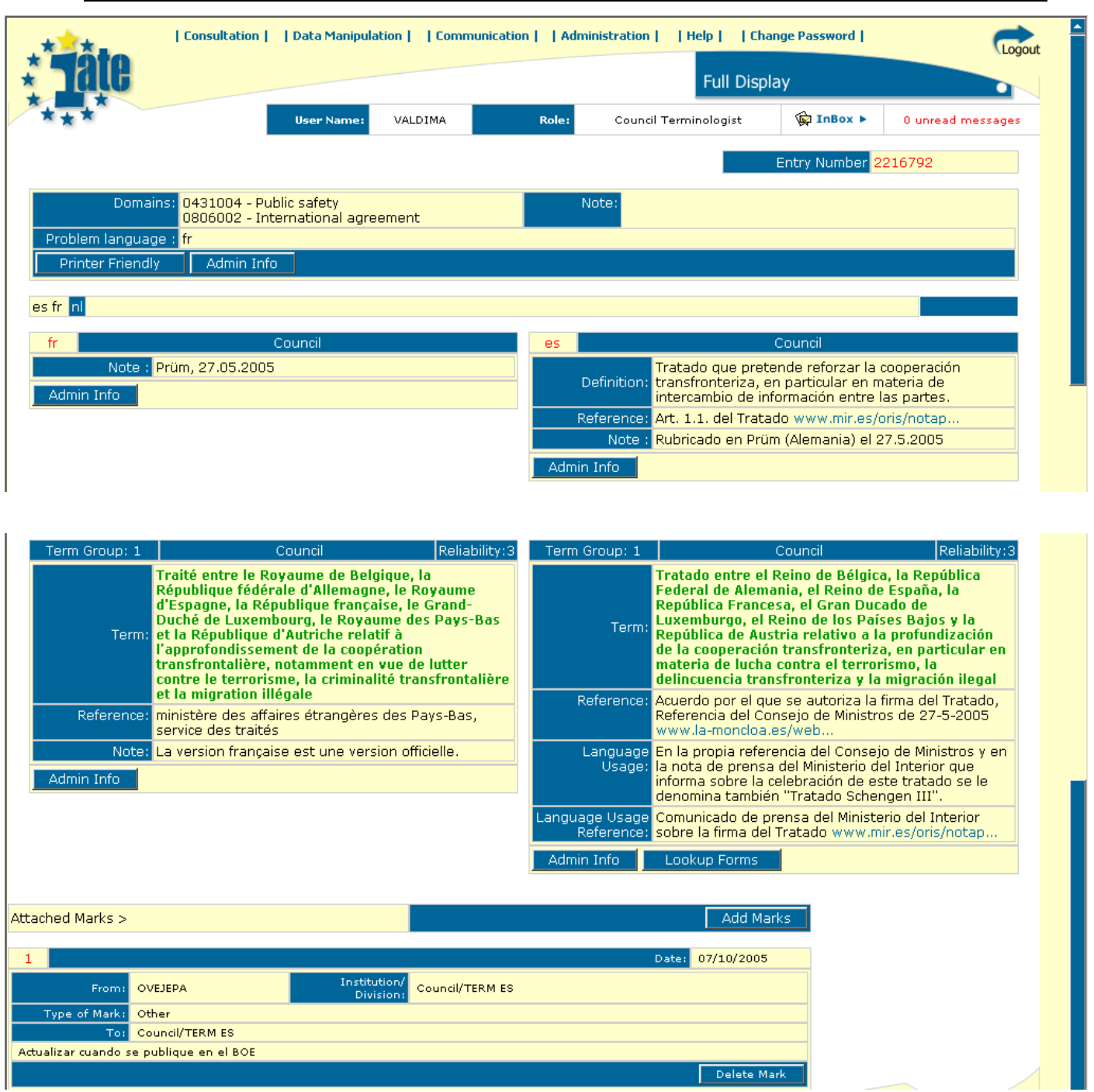

Fig. 4: LATE-Ficha abierta con aviso

\subsubsection{Normas}

Los principios que rigen la alimentación de IATE están plasmados en dos documentos:

1. Normas de escritura. Son los criterios formales de introducción de datos. Definen cada uno de los campos de la ficha y explican cómo debe ser su contenido.

2. Directrices o código. Son los principios básicos de la práctica terminológica de las instituciones en IATE. Deben servir de 
guía para el trabajo terminológico y facilitar la coherencia interinstitucional de la base.

Como ejemplo, podemos destacar algunos de estos principios:

- Multilingüismo. Las fichas han de tender a ofrecer el mayor número de lenguas oficiales posible.

- Pertinencia. Los términos introducidos deben corresponder a un posible problema de redacción o traducción en la UE.

- Utilidad específica. IATE debe aportar algo específico en relación con otras fuentes documentales.

- Precisión. La información aportada debe corresponder con la mayor exactitud posible al concepto ya presente en la ficha.

- Concisión. El término debe constituir la unidad indivisible más pequeña para designar un concepto concreto.

\subsubsection{Estructuras de gestión}

Se han puesto en marcha estructuras y procedimientos de cooperación interinstitucional con miras a la gestión integrada de la base.

\subsubsection{Algunos ejemplos de problemas que LATE necesita resolver}

A fin de dar una idea concreta del desafío que entraña IATE para la actividad terminológica de las instituciones bastará enumerar algunos ejemplos concretos:

- Los distintos enfoques y prácticas de cada institución, que responden a menudo a necesidades específicas, deben armonizarse.

- La interacción, en una misma ficha, de las terminologías de unas instituciones y otras y de diferentes idiomas debe encontrar una pauta eficaz, hoy por hoy inexistente por definición (¿quién puede hacer qué en una ficha de otra institución?).

- La tarea de limpiar y racionalizar una base heteróclita como resultado de la yuxtaposición ya referida es ingente, pero primordial.

- La posible articulación con otros fondos documentales y terminológicos exteriores plantea ciertos problemas técnicos, jurídicos y organizativos.

- La participación de especialistas externos en la alimentación de la base debe estudiarse y resolverse. 


\section{PERSPECTIVAS Y CONCLUSIONES}

Con todo lo anterior, son fáciles de imaginar los retos que supone llevar a buen puerto una base terminológica multilingüe común, alimentada por equipos de distintas instituciones, condicionados por las necesidades de sus respectivos servicios de traducción y por dinámicas y trayectorias también distintas, articulándose al mismo tiempo con otros tantos equipos de otras veinte lenguas.

IATE se halla en un momento decisivo de su corta historia y no tiene despejado el horizonte. Puede convertirse en el utensilio terminológico de referencia al servicio de especialistas, traductores, técnicos y público en general, constituyendo el instrumento imprescindible para que la UE responda al derecho de sus ciudadanos a disponer de una legislación de calidad en su propia lengua. Pero, para ello, las instituciones deben dedicar los recursos suficientes, colaborar eficazmente, armonizar sus distintas "culturas" y prácticas terminológicas, adaptar y limpiar sus respectivas "herencias" heterogéneas y converger en una dinámica flexible, a la vez que englobadora y efectiva. Así tendrá plena plasmación el multilingüismo reconocido desde los textos fundacionales como uno de los cimientos de la Unión Europea. 